\title{
UNA UNIDAD MILITAR EN LOS ORIGGENES DEL FASCISMO EN ESPAÑA: LA LEGIÓN
}

\author{
José L. Rodríguez Jiménez
}

\section{INTRODUCCIÓN}

En el verano de 1921, inmediatamente después de la derrota en Annual, un sector del conservadurismo español, el más identificado con la nueva derecha autoritaria y nacionalista que irrumpe con fuerza en el escenario europeo, inicia una campaña de exaltación de una unidad militar de reciente creación y destinada a la guerra en Marruecos, el Tercio de Extranjeros o Legión. Sin embargo, en noviembre de 1922 el jefe de la Legión, teniente coronel José Millán Astray, presenta la dimisión y solicita el pase a la situación de retirado. Esta iniciativa, auténtica provocación al Gobierno, forma parte de una estrategia diseñada por esa derecha, en cuyas filas figuran varios de los promotores del colonialismo español, que exigen que se dé continuidad a la campaña en Marruecos hasta la victoria definitiva sobre las fuerzas indígenas que manda Abd-el-Krim. Sólo así, argumentan, sería posible recuperar el orgullo nacional y proceder a la explotación económica de ese territorio, cuestión que ha ganado en importancia desde el momento en que, una vez finalizada la guerra en Europa, ha disminuido drásticamente el volumen de negocios al que han tenido acceso las empresas españolas ${ }^{1}$. Para ello sería preciso liquidar la influencia de las Juntas de Defen$\mathrm{sa}^{2}$, asociación del arma de Infantería nacida en el contexto de la crisis de 1917 para exigir la renovación de la vida política pero también, cada vez más, para canalizar sus reivindicaciones corporativas, relacionadas con el mantenimiento

1. Sobre las empresas españolas con intereses en las minas del Rif y el conjunto del protectorado, véase MORAles LezCANO, Víctor., El colonialismo hispanofrancés en Marruecos (1898-1927), Madrid, 1976, especialmente los caps. 2 y 3; y MADARIAGA, M. ${ }^{2}$ Rosa de, España y el Rif. Crónica de una historia casi olvidada, Melilla, 2000, pp. 125-147.

2. En realidad, en enero de 1922 Maura, como jefe de Gobierno, y La Cierva, ministro de la Guerra (antes favorable a los junteros), consiguen la reconversión de las juntas en comisiones informativas integradas en el Ministerio de la Guerra y sometidas por tanto al código de justicia militar. 
del poder adquisitivo de la oficialidad y la aplicación de una escala cerrada. Los junteros se muestran muy críticos con la profusión de condecoraciones, premios en metálico y ascensos en beneficio de los compañeros que prestan servicio en el norte de África, lo que les enfrenta a éstos, a los africanistas; reciben este apelativo los jefes y oficiales que han solicitado ese destino y son partidarios de proseguir las operaciones militares en Marruecos y de los ascensos por méritos de guerra. Sería necesario, además, dar carpetazo al expediente que sobre los sucesos ocurridos en la comandancia general de Melilla ha terminado de redactar, por orden del Gobierno, el general Picasso y que debe ser llevado a las Cortes para su discusión y determinación de responsabilidades por lo ocurrido en Annual. De forma que entre los militares africanistas y los políticos que actúan de portavoces de los intereses coloniales se forja una red de relaciones y de intereses mutuos, y dos de los jefes de la Legión, el teniente coronel Millán Astray y el comandante Francisco Franco, son utilizados como estandartes de lo que debe hacerse en Marruecos. Y al mismo tiempo la Legión aparece identificada no con los postulados de un Gobierno, algo imposible dada la escasa duración de los gabinetes de aquella época, ni siquiera con el conjunto de las fuerzas de la derecha, pues la derecha española se haya profundamente dividida a nivel programático e ideológico, sino con una de las corrientes de la derecha, aquella que se desborda en entusiasmo ante la estrategia seguida por el fascismo italiano en su camino hacia el poder. Por este motivo nos parece interesante reflexionar sobre la identificación de la Legión con un movimiento político ${ }^{3}$, el maurismo, y sobre el papel desempeñado por el jefe de esta unidad, con el respaldo de, al menos, una parte de sus oficiales en la agitación de la calle a manos de los precursores del fascismo en España.

\section{LA LEGIÓN, UNIDAD MILITAR ESPECIAL Infantería de choque para la guerra de Marruecos}

Ya antes de la crisis del 98, en el contexto del reparto de África propiciado por el colonialismo europeo, se ha manifestado el interés de ciertos sectores políticos y económicos españoles por obtener el dominio de territorios en el continente africano. El tratado firmado con Francia en 1904 para el reparto de Marruecos en zonas de influencia y su ratificación en 1912, para el establecimiento de un régimen de protectorado, viene a satisfacer las expectativas de grupos que operan en un Estado cuyo peso es muy escaso en el escenario internacional. Para entonces el interés por la zona que ha correspondido a España, que es la septentrional, ha aumentado en el mundo empresarial, por la riqueza minera y las obras de infraestructura que podrían llevarse a cabo, entre los políticos monárquicos, deseosos de forjar de nuevo una imagen prestigiosa de España en el plano internacional, una parte de los cuales actúan en connivencia con grupos

3. Recogemos así un debate apuntado por UCELAY DA CAL, Enric, "Los orígenes del fascismo en España: El militarismo", en FONTANA, J., Història i projecte social. Reconeixement a una trajectòria, Barcelona, 2004, pp. 1380-1410. 
económicos, y también entre los oficiales y jefes del ejército, pues una nueva campaña supondría la posibilidad de combatir de nuevo, alcanzar una victoria en el campo de batalla, ascensos y honores y acallar las duras críticas recibidas por la derrota del 98; además, el muy joven e inexperto rey Alfonso XIII, coronado en 1902 con 16 años, es muy favorable a la empresa colonial.

Pese a que se combate frente a fuerzas carentes de instrucción militar y de armamento pesado, que rechazan la autoridad del sultán y la presencia extranjera en su país, la evolución de las operaciones militares es muy poco satisfactoria para España. Esto obliga a una reflexión sobre la capacidad de un ejército basado en el servicio militar obligatorio, pero del que se libran los hijos de las familias que más patriotas se declaran, es decir, las que disponen del dinero necesario para pagar la sustitución o redención a metálico. Precisamente la mala marcha de la guerra y la desigualdad del servicio en filas dan lugar a sucesivas campañas de protesta que, impulsadas por socialistas y republicanos, cuentan con un amplio apoyo entre la población, no circunscrita a la izquierda política. Se plantea entonces la necesidad de contar con un ejército colonial nutrido de voluntarios, al estilo del que poseen Gran Bretaña, Francia y otros países. Nacen así, en 1911, las fuerzas de Regulares Indígenas. Pero las fuerzas indígenas son de momento escasas en número, por lo que apenas se atenúa el problema de las bajas españolas, y en muy escasa medida se progresa en la ocupación del territorio. Además, en 1912 se modifica el sistema de reclutamiento y se suprime la redención mediante el pago de una cantidad de dinero. De forma que ahora existe la posibilidad de que los hijos de las familias con mayores recursos sean destinados a Marruecos. Por ello los partidos dinásticos van a poner en marcha otras iniciativas para que el servicio en Marruecos sea cubierto con voluntarios. Una vez fracasado el sistema de soldado-colono, el de los voluntarios con premio, a base de un incentivo con tierras una vez cumplido el servicio, en 1918 el Estado Mayor Central comienza a trabajar en la organización de una nueva unidad de infantería, según el modelo de la Legión Extranjera Francesa. Y en enero de 1920 un real decreto establece el llamado Tercio de Extranjeros, al que sus jefes y oficiales denominan Legión.

\section{El espiritu legionario}

El teniente coronel Millán Astray figura entre los militares que más empeño ha puesto en reivindicar la necesidad de una unidad de infantería de choque a base de voluntarios extranjeros y españoles para ser empleada en el norte de África. Con este propósito ha visitado el Ministerio de la Guerra y se ha ofrecido para organizar y mandar a la nueva tropa. No sólo eso, una vez que la Legión es una realidad y él es ascendido a teniente coronel y puesto al mando, va a reivindicar como propio el proyecto: él habría sido el primero en sentir su necesidad y el primero en plantearla en medios militares. Millán Astray se esfuerza, además, en dotar a la Legión de un estilo propio, bronco y aguerrido, que trascienda la mentalidad africanista, ultraconservadora y militarista, que concibe la guerra, en un mundo supuestamente siempre en conflicto, como escuela para 
la vida, algo vital y heroico ${ }^{4}$. Al propósito de que la Legión se distinga del resto de unidades de infantería responden el nombre original, Tercio de Extranjeros, en recuerdo de los tercios, que fueron la base del sistema militar español del siglo XVI, el uniforme verde grisáceo, la camisa de cuello abierto, el gorro con borla, el himno (La canción del legionario), las canciones (La Madelón, El novio de la muerte), los gritos (Viva la muerte!), los guiones de las banderas (nombre que reciben los batallones), las mascotas, el régimen disciplinario, de extrema dureza en los castigos, a menudo físicos, y lo que Millán Astray concibe como liturgia legionaria. Una liturgia conformada por un conjunto de poses, gestos y una retórica, resumida en el Credo legionario, con la que pretende transmitir a los voluntarios un sentimiento tribal, de pertenencia a una colectividad guerrera capaz de vivir con intensidad el compañerismo, el sufrimiento, el deseo de superación y la proximidad de la muerte. Uno de los espíritus del Credo legionario plantea el culto a la muerte, el cual será consustancial a la Legión:

"El espíritu de la muerte. El morir en el combate es el mayor honor. No se muere más que una vez. La muerte llega sin dolor y el morir no es tan horrible como parece. Lo más horrible es vivir siendo un cobarde».

Millán Astray se referirá de forma reiterada a la posibilidad de la muerte de los legionarios en combate, que resulta ser casi una exigencia en sus arengas: "La Legión os pide sin escrúpulos y sin miramientos que muráis por una causa que ella defiende y en virtud del compromiso que habéis firmado». Rinde así culto no sólo al valor y al sacrificio por la patria, sino también a esa especial circunstancia de la vida que es la muerte, la cual cumpliría el papel de igualar a todos los mercenarios y, lo más importante, diluir el hecho de que se trata de mercenarios. La muerte, tras igualar a todos, abre las puertas a la redención: quedan redimidos de un pasado turbio y lleno de amarguras los que entregan su vida por la patria española, que, entre tanto, a la espera de ese momento, ya los acoge. Este culto a la muerte, asumido por el conjunto de la oficialidad legionaria, es propio de la época en la que nos encontramos, cuando destacados filósofos e intelectuales europeos hacen bandera del irracionalismo y de la primacía de la fuerza, el instinto y las pasiones sobre la razón. Es además algo muy presente en el ideario de algunas de las organizaciones de ex combatientes de la guerra mundial y muy especialmente, en el plano de los discursos y de la simbología (la calavera y las tibias), en los arditi, precursores de las primeras escuadras fascistas en Italia, y en los freikorps que colaboran en la derrota de la revolución espartaquista en Alemania y procuran después desestabilizar la República de Weimar, al igual que lo estará en varias de las secciones del Partido Nazi, hasta llegar al anillo Totenkopf, o de la calavera, reservado a los veteranos de las Escuadras de Seguridad o SS; la calavera, compañía inseparable de los

4. Sobre las relaciones entre el ideario de la Legión y la derecha antiliberal y la extrema derecha véase GALEY, J. H., "Bridegrooms of Death. A Prufile Study of the Spanish Foreign Legion", Journal of Contemporary History, vol. 4, n. 2 (abril 1969), pp. 47-64; y RODRíguez, José Iuis, jA mi la Legión! De Millán Astray a las misiones de paz, Barcelona, 2005. 
miembros de estas milicias políticas, simboliza la obediencia, la hermandad, la camaradería y la voluntad de entregar la vida en cualquier momento por el bien de la nación, el pueblo o la raza.

\section{La Legión en los medios de comunicación de la derecha autoritaria. Franco, el hombre de los colonialistas}

Lo ocurrido en Annual, al este de Melilla, en el verano de 1921, la derrota y la masacre de las tropas que manda el general Fernández Silvestre a manos de las harkas rifeñas, con el resultado de más de 8.000 españoles muertos, supone una nueva catástrofe militar que añadir a la reciente historia española. Cuando tiene lugar el desastre de Annual y el desmoronamiento del dispositivo militar de la zona oriental del protectorado, las tropas legionarias acaban de salir del período de instrucción y participan en sus primeros combates en la zona occidental del protectorado. Se trata para entonces de una unidad militar desconocida para los españoles. Sin embargo, las noticias llegadas a la península sobre la derrota sufrida en tierras africanas, sitúan a la Legión en el primer plano de la actualidad. La Legión aporta una buena carta de presentación: sus contingentes figuran entre los primeros refuerzos recibidos por la ciudad de Melilla, los cuales consiguen levantar la moral de unas gentes presas del pánico, y durante los meses siguientes, las banderas legionarias ocupan la vanguardia de las operaciones puestas en marcha para la recuperación del territorio perdido. Además, la opinión pública, y sobre todo la oposición republicana y socialista, exige responsabilidades por lo ocurrido. A los mandos militares les llueven las críticas, por el grave error cometido por Fernández Silvestre en la planificación de las operaciones, sin que el alto comisario en Marruecos, general Dámaso Berenguer, imponga la autoridad que se le supone en la dirección de la campaña, y por otras cosas que se van sabiendo, que incluyen un alto grado de corrupción en la comandancia. De la quema se salvan pocas unidades, y dado que una parte de los Regulares se han pasado a Abd-el-Krim, la imagen de la Legión sale muy favorecida. Conforme van llegando noticias del desastre se habla más del Tercio, al que una parte de los medios de comunicación atribuyen el papel de vengador de las crueldades cometidas por los rifeños con los soldados españoles que se han rendido en Monte Arruit, Zeluán y otras posiciones. Si de lo que se trata, se nos dice, es de derrotar al cabecilla rifeño e infringir a las tribus que le siguen un duro castigo, para ello nada mejor que una fuerza de primera línea formada por mercenarios sin miedo a la muerte, como decía la propaganda legionaria. De hecho así va a ser. La infantería de choque, la Legión y Regulares, asumen las tareas de mayor riesgo, en vanguardia cuando se avanza para la ocupación de posiciones, después de lo cual se procede a la eliminación de los prisioneros y a la destrucción de los poblados del enemigo, y en la retaguardia cuando es preciso cubrir el repliegue de otras unidades.

Así las cosas, ante la necesidad de crear héroes militares para los relatos con los que se intenta convencer a la opinión de la necesidad de la campaña militar, la prensa monárquica y los semanarios de actualidad gráfica destinados al en- 
tretenimiento de las clases medias traen a la Legión a sus páginas como noticia, y también como resorte para la recuperación del orgullo nacional herido, y pronto lo harán, asimismo, una serie de novelas. Muy especialmente lo hacen aquellos medios favorables a la explotación colonial del territorio marroquí y tentados por las propuestas de la emergente derecha autoritaria, aquella que reniega del conservadurismo liberal y apuesta por fórmulas de gobierno basadas en un ejecutivo fuerte y cámaras de representación corporativa. Uno de los jefes legionarios, el comandante de la I bandera, Franco, recibe una atención especial. Que Franco haya sido elegido como imagen de un proyecto militar, la campaña de Maruecos, que lo es a su vez económico y político, tiene que ver con las circunstancias de la guerra. Millán Astray resulta herido de gravedad, de un disparo en el pecho, a mediados de septiembre de 1921, al poco de ponerse en marcha las operaciones que tienen Melilla como punto de partida. Franco queda entonces como jefe interino en el preciso momento en que se recuperan las posiciones perdidas; $y$ aunque el jefe del Tercio regresa al frente dos meses después, una nueva herida, ahora en la pierna derecha, y el hecho de que se le reabra la herida en el pecho, obliga a su traslado a Madrid en enero de 1922, no regresando al teatro de operaciones hasta el mes siguiente, cuando las operaciones de reconquista del territorio del entorno de Melilla casi han terminado; entretanto Franco se forja una muy buena imagen entre sus compañeros africanistas y es citado muy elogiosamente en los diarios de operaciones. También con el hecho de que Franco no ha cursado estudios de Estado Mayor, posee una escasa formación cultural, ofrece una imagen de joven y tímido jefe militar y se le ve como a alguien a quien se puede manejar con facilidad. A comienzos de 1922 el nombre de Franco salta de la prensa ceutí y melillense a la de Madrid, nada menos que a las páginas salidas de los talleres de Prensa Española, el grupo editor de $A B C$, el de mayor tirada del país, y el semanario Blanco y Negro, que lo presenta como «El as de la Legión $»^{5}$. Se trata del grupo que, junto a la prensa maurista, más presión ejerce sobre el Gobierno, dividido a este respecto, para que se decida a imponer un duro castigo a los rifeños y a hacer del protectorado una realidad. En todos los lugares de España proliferan en estas fechas los agasajos a los oficiales heridos en la campaña o que disfrutan de unos días de permiso. Pero a Franco, en el papel de ídolo de los colonialistas, se le dedican muchísimas más noticias que a otros comandantes, y de bastante más extensión, y aparece muchas más veces que coroneles o generales que también tienen destino en el protectorado.

Durante varias semanas de febrero-marzo de 1922 Franco, con permiso para viajar a Galicia y Asturias, para pasar unos días junto a su madre y su novia, es objeto de continuada atención desde $A B C$, sobre todo cuando se detiene en Madrid, donde se le ofrece un homenaje en el hotel Ritz. En la presidencia de la mesa Franco está acompañado de varios jefes y oficiales y de dos ex ministros. Uno de ellos es Antonio Goicoechea, cabeza visible de la derecha maurista. Y

5. Artículo de Corrochano, Gregorio, $A B C, 22$ de febrero de 1922. 
entre las adhesiones recibidas figura la de Álvaro de Figueroa, conde de Romanones, dirigente del partido liberal y, como su hermano Gonzalo, con presencia de capital en la Compañia Española de Minas del Rif y otras empresas mineras que han comprado concesiones en el entorno de Melilla. Mury próximos a Franco también aparecen el periodista de $A B C$ Gregorio Corrochano, quien cubre las crónicas sobre la guerra de Marruecos y es quien, muy posiblemente ${ }^{6}$, se ha encargado de escribir el libro Marruecos. Diario de una bandera, que aparece a finales de año con la firma de Comandante Franco, y el periodista y escritor Víctor Ruiz Albéniz, autor de varios textos sobre la campaña militar que satisfacen los intereses del conde de Romanones ${ }^{7}$. Franco también es llevado a las páginas de las revistas gráficas Nuevo Mundo, Mundo Gráfico y Blanco y Negro. Este tipo de homenajes se repetirán meses después, por dos veces en los salones del hotel Palace, es decir, siempre en los escenarios más lujosos de la capital, lo que lleva a Franco a la portada de $A B C$, además de ser recibido por el rey Alfonso XIII, quien le nombrará gentilhombre de cámara. El nombre de Franco también lo encontramos, repetidas veces y citado siempre de forma muy elogiosa, en las páginas de El Debate, órgano de Acción Católica Nacional de Propagandistas (ACNP) y muy favorable a Maura ${ }^{8}$ y, en mayor medida, en La Acción, el portavoz del movimiento maurista en Madrid.

Sin embargo, durante los meses siguientes los portavoces de la derecha autoritaria, en concreto del maurismo, van a desplazar su atención desde Franco a Millán Astray, el jefe de la Legión, ya recuperado de sus heridas y quien dispone de mayor disponibilidad para viajar y desplazarse a la capital del Estado y sobre todo de una más amplia red de relaciones y de una capacidad para cuestiones de propaganda de las que carece su subordinado. Así, Millán Astray, con el grado de teniente coronel, ni siquiera general, actúa como punta de lanza de los intereses de la derecha ultranacionalista y colonialista, logrando colocar al Gobierno bajo presión. Quienes exigen la continuidad de la campaña militar apuntan en concreto la ocupación de Alhucemas, operación que se considera necesaria en términos militares, políticos y económicos. En términos militares supondría, según se dice, asegurar el control de toda la costa norte del protectorado y someter a las tribus que más se han significado por su rechazo a la presencia extranjera. En términos políticos permitiría mostrar al mundo que España es capaz de desarrollar una acción colonial y recuperar el honor, lo que exige, antes que nada, «imponer un castigo ejemplar para que no se olvide que impunemente no puede realizarse contra hermanos nuestros una felonía

6. Rodríguez, José Luis, Franco. Historia de un conspirador, Madrid, 2005, pp. 63-66.

7. Véase su dedicatoria "Al Excmo. Señor Conde de Romanones» contenida en España en el Rif, Madrid, 1921.

8. Con fecha de 25 de octubre de 1922 los editores declaran que El Debate "no es órgano oficioso del señor Maura» pero siente por él una especial veneración y está "identificado con el ilustre estadista en muchos puntos fundamentales" y le considera "el político con más aptitud para presidir un gobierno». 
como la de Monte Arruit»". En contraste con la profusión de textos dedicados a la rentabilidad militar y política de la ocupación del territorio adjudicado a España en los tratados suscritos con Francia y Gran Bretaña, es curioso que casi nunca los políticos españoles hagan referencia a lo que, en su opinión, podría proporcionar el protectorado en términos económicos, y eso que la campaña militar está suponiendo cuantiosos gastos que lastran las cuentas del Estado. De entre quienes se muestran favorables a dar continuidad a la campaña, el político que con mayor claridad se refiere al tema económico es Goicoechea. Lo hace en varias ocasiones para apuntar que España debe obtener «ayudas que sirvan para indemnizar los gastos que se hacen hoy en beneficio del pueblo marroquí y a costa exclusiva de España". Dando por veraces, por mera conveniencia, los relatos sobre la riqueza del territorio debidos a viajeros y aventureros que décadas atrás pasaron por estas tierras, Goicoechea escribe que, aparte de la existencia de tierras fértiles en el interior,

«la región de Beni-Urriaguel, punto natural de enlace de los ferrocarriles de Tetuán a Ceuta y de Melilla a Tistutin y Drius, encierra inmensas riquezas mineras inexplotadas. Todos los viajeros, desde Roland Trejus, que visitó África en el siglo XVII, a los más recientes exploradores, como el vizconde de Toucauld y Moulieras, hacen alusión a la riqueza ferruginosa, análoga a la de Beni-bu-lfrur, del suelo de la región central. Moulieras llega a hablar de la existencia alli de un nuevo Transvaal» ${ }^{10}$.

\section{LA LEGIÓN Y LA DERECHA AUTORITARIA NACIONALISTA El contexto político nacional e internacional}

Retrocedamos unos años para entender la estrategia de los mauristas en esta coyuntura. A finales del XIX el régimen de la Restauración ha entrado en crisis y los dos partidos dinásticos que son la base del sistema político se adentran en lo que será un largo proceso de desintegración. A esta situación, y a las propuestas regeneracionistas animadas por la intelectualidad conservadora y progresista, hay que sumar el desafio al sistema de los movimientos socialista y anarquista. La crisis abierta afecta no sólo al sistema de partidos sino también a la propia monarquía, aunque ésta sufre por el momento daños limitados porque los sectores reformistas moderan sus críticas justamente para no provocar una ruptura definitiva del sistema. No obstante, las distintas corrientes regeneracionistas ganan terreno y movilizan, de forma limitada, a sectores de las clases medias. Este discurso incorpora en ocasiones llamadas a un Gobierno fuerte, autoritario, imprescindible, se dice, para poner fin al fraude de una vida política viciada por los partidos establecidos. En este contexto se sitúa la figura de Antonio Maura,

9. «El problema de Marruecos», $A B C, 15$ de febrero de 1922. Un año después, el 4 de febrero de 1923: "no puede quedar sin venganza inmediata, rápida y ejemplar, la villanía, la barbarie, la crueldad, la codicia de una morisma salvaje que se ha gozado en la tortura de nuestros hermanos indefensos».

10. GoICOECHEA, Antonio, "El problema de Marruecos. Alhucemas y la implantación del protectorado", La Acción, 3 de noviembre de 1922. 
quien alienta la renovación tanto del partido conservador, del que es uno de los principales dirigentes, como del conjunto de la vida política. Hasta entonces los conservadores, y lo mismo cabe decir de la mayor parte de los liberales, apenas habían demostrado interés por presentar una alternativa a la crisis. Maura, en cambio, expresó su predisposición a la reforma, estando dispuesto a enfrentarse al sistema existente "desde una óptica de derecha»" ${ }^{11}$. Fue el primer político conservador de relieve que se decidió a «predicar una moderna forma de hacer política, apelando a las masas», y no cabe duda de que el componente más duradero de su propaganda fue "la apelación a la movilización de la ciudadanía»" entendiendo ésta de forma limitada, pues no contemplaba la incorporación a la vida política del proletariado urbano y campesino. Y aunque los deseos de Maura de una revolución desde arriba no cristalizaron y su imagen de gobernante quedó arruinada por la represión de la Semana Trágica en 1909, surgió un movimiento alrededor de su persona, el maurismo, el cual dejó su impronta en la aparición de dos nuevas manifestaciones de la derecha que se van a esforzar en reconquistar el terreno perdido: un catolicismo social renovado, que encarna Ángel Osorio, y un nacionalismo autoritario bajo la batuta de Goicoechea.

El maurismo, en tanto que corriente organizada, desde finales de 1913, tiene su origen en la rebelión interna producida en el seno de la Juventud Conservadora, que cambia su nombre por el de Juventud Maurista cuando Maura dimite como jefe del partido conservador. Maura pretendía con este paso expresar su repulsa al hecho de que la oposición de los liberales, reformistas, republicanos y socialistas a la posibilidad de que él regrese a la jefatura del Gobierno hubiese decidido al rey, en su búsqueda de una alternativa, a confiar el Gobiemo a los liberales y después al conservador Eduardo Dato, y que éste hubiese aceptado. En 1914 se produjo la división definitiva del partido conservador. Los mauristas crearon una estructura organizativa, se dotaron de medios de prensa, dieron vida a varios centros obreros, y compitieron en las elecciones a Cortes y a una serie de Ayuntamientos, en varios de ellos con éxito, como es el caso de Madrid. Además, el maurismo, nacionalista, católico confesional, intervencionista en el ámbito económico e influido por los pensadores de la derecha francesa que conciben la sociedad como un organismo obligado a coordinar su defensa frente a la subversión izquierdista, introdujo nuevas formas de actuación en política, como eran sus despliegues de propaganda, los mítines y los centros de carácter formativo y didáctico para militantes. También ayudó a renovar el léxico de la derecha española, enriqueciéndolo con referencias a la explotación de los trabajadores por el capitalismo, y expresiones y términos como gesto de rebeldia, deber, sacrificio y revolución, asignando a este último un sentido positivo, en la línea de la nueva derecha autoritaria y el fascismo. Paulatinamente los mauristas fueron radicalizando sus posiciones, en sentido autoritario, en

11. TUSELL, J. y AVILÉS, J., La derecha española contemporánea. Sus origenes: el maurismo, Madrid, 1986, p. 11 .

12. Tusell, J., Antonio Maura. Una biografia política, Madrid, 1994, p. 53. 
respuesta a la crisis del sistema político, y alentaron un Gobierno dictatorial, con Maura o sin Maura, que supondría la marginación del parlamento y de los partidos, alegando la imposibilidad de regenerar el país dentro del orden constitucional. Goicoechea, presidente de la Juventud Maurista de Madrid, ministro de la Gobernación en 1919 (en el penúltimo Gobierno de Maura) y jefe de las filas mauristas tras la salida de Osorio en 1922 para fundar el Partido Social Popular, propone en sus discursos y escritos una "democracia conservadora" $y$ orgánica ${ }^{13}$, eufemismo retomado por el franquismo, régimen en el que tendrá un importante papel el propio Goicoechea.

Precisamente la Juventud Maurista celebra su tercera, y última, asamblea entre el 20 y el 30 de octubre de 1922, muy pocos días antes por tanto de los hechos a los que nos vamos a referir. En los días previos a la asamblea maurista otra organización representativa de la derecha antiliberal, y muy vinculada a la jerarquía eclesiástica, la ACNP, acaba de repetir su llamada a una "unión de los grupos derechistas», entendiendo por tales no los partidos dinásticos sino a los tradicionalistas (antidinásticos), mauristas y populares, denominación esta última que hace referencia al proyecto lanzado por Ossorio: «Divididos, jamás seremos un factor de peso en la política; unidos, podremos ser acaso en pocos años los árbitros de los destinos de España ${ }^{14}$. Pues bien, el manifiesto que la comisión organizadora de la asamblea maurista hace llegar a las organizaciones provinciales incluye una propuesta de debate en torno a los siguientes temas: las repercusiones en España de la "hora grave y solemne en que Europa se detiene atónita ante el caos" (referencia al triunfo de la revolución comunista en Rusia y al avance de los partidos comunistas y socialistas en Europa occidental), "el ansia de transformación política que aletea alrededor de nuestro propio partido", la conveniencia "de encargar la dirección del partido a una sola persona", que será Goicoechea, y el maurismo como «base de la necesaria unión de las fuerzas sociales derechistas para formar un gran partido político".

Debe apuntarse también que la crisis a la que a continuación nos vamos a referir, provocada por quienes pretenden configurar un partido capaz de representar a todos los sectores de la derecha antiliberal, tiene lugar inmediatamente después de que el líder fascista Benito Mussolini acceda a la jefatura del Gobierno de Italia. Y de esto se habla, y mucho, en los círculos políticos españoles. Los portavoces de la derecha autoritaria se muestran favorables a la adopción de algunos de los rasgos definitorios del fascismo, sobre todo, en mayor medida que los referidos a los contenidos doctrinales, aquellos que se refieren a su estrategia de acceso al poder y a las prácticas utilizadas para destruir a las organizaciones de la izquierda. Obviamente, esta última cuestión ha sido planteada con anterioridad en medios de la derecha, principalmente por los sindicatos católicos, los mauristas y figuras del empresariado: en el contexto de la crisis de 1917 el marqués de Comillas, tras intervenir en la reorganización del

13. GolcoecheA, Antonio, Hacia la democracia conservadora, Madrid, 1914 14. "La condición del éxito", editorial de El Debate, 6 de octubre de 1922. 
somatén en Barcelona, patrocina en Madrid la denominada Defensa Ciudadana de la Villa y Corte de Madrid, una fuerza voluntaria dotada de armas y vehículos blindados con los que proteger edificios e instalaciones si la izquierda obrera convocase una huelga general o desatase un movimiento insurreccional ${ }^{15}$. El portavoz de la ACNP, El Debate, pone reparos a los procedimientos utilizados por el fascismo antes de la toma del poder, apuntando algunos excesos, dado que la violencia fascista también la sufren los miembros del Partido Popular, el partido católico, núcleo todavía del Gobierno italiano, pero esos reparos desaparecen, en su mayor parte, cuando los fascistas acceden al Gobierno y se centran en el ejercicio del poder político, la exaltación nacionalista y la defensa de la monarquía y la religión católica. Esas mismas consideraciones aparecen en las páginas del principal diario monárquico, $A B C$. En cambio, los reparos son mínimos en las páginas de La Acción, diario de la noche en Madrid y principal portavoz del maurismo. Su director, Manuel Delgado Barreto, quien escribe bajo el seudónimo de Duque de G, va a promover "un fascismo a la española" capaz de poner fin a los usos de la vieja política. Piezas de esta estrategia son una serie de editoriales que contienen duras críticas a la clase política gobernante, y una llamada a agitar la calle según los parámetros del fascismo, definido como «revolución adecentadora y reconstructora»: dado que no ha sido posible la revolución desde arriba preconizada por Maura, debe abrirse paso el "maurismo callejero", es decir, la Juventud Maurista, armada de garrotes y bastones, ha de proceder a una obra "de agitación y de estruendo» ${ }^{16}$; a algo muy distinto, por tanto, de la labor de vigilancia armada en torno a los edificios religiosos y públicos de la capital iniciada años atrás por los integrantes de Defensa Ciudadana en previsión de una rebelión de la izquierda, pues de lo que ahora se trata es de que el voluntariado civil adopte el estilo de las milicias fascistas en el sentido de forzar la claudicación de las autoridades y un cambio de régimen. Por su parte Goicoechea se encarga de incidir en el supuesto paralelismo entre las situaciones vividas en la Italia prefascista y España, y en la necesidad de abrir las puertas a un régimen que guarde estrechas similitudes con el fascismo. En España, escribe Goicoechea, el fascismo "podría denominarse de unión española y aún de unión sagrada de todos los españoles de buena voluntad»; así la salida de la crisis, y el fortalecimiento de la monarquía (la monarquía helena acaba de ser derribada por su responsabilidad en un desastre colonial), pasa por el empleo de la violencia, una violencia que se entiende ha de salir de la sociedad civil dado que, a diferencia de otras coyunturas, no hay una invocación directa a la intervención de las fuerzas armadas, que deberían limitarse a dejar hacer, como en Italia:

15. GONZÁlez CALLEJA, Eduardo, epígrafe "La defensa social contra la revolución en Madrid", en El máuser y el sufragio. Orden público, subversión y violencia política en la crisis de la Restauración (19171931), Madrid, 1999, pp. 88-103.

16. "La significación fascista y el anhelo español», La Acción, 30 de octubre de 1922. 
«Es doloroso llegar a la consecuencia de que sólo por violentas sacudidas es posible poner a España en condiciones de vivir y de prosperar, limpia de la roña política que la corroe y que la avergüenza.

En Italia, después de los días de conmoción que ha producido el avance fascista, renace la tranquilidad y el país se siente libre de la pesadilla intolerable de su vieja y desorganizada política.

Que así sea en España, y que todos los que tienen la obligación de ayudar con su actividad o con su discreta inhibición tal movimiento, cumplan esas obligaciones patrióticas, para honra del nombre nacional y para consolidación de las instituciones fundamentales ${ }^{17}$.

\section{Millán Astray pide la baja en el ejército}

La actuación política de Millán Astray resulta posible por la debilidad de los gobiernos de la época, en plena crisis del sistema de la Restauración, cuando el turno de partidos entre conservadores y liberales forma parte del pasado $y$, desde seis años atrás al menos, se ha hecho evidente que ninguno de los dirigentes de las formaciones dinásticas es capaz de imponer disciplina en sus propias filas, por lo que, en ocasiones, se acude a la fórmula de gobiernos de concentración nacional, de los que forman parte las principales figuras de los dos partidos dinásticos. Por lo que a los conservadores se refiere, tras el asesinato de Dato por terroristas anarquistas en 1921, el partido quedó escindido en tres fracciones: el maurismo y los grupos tutelados por Juan de la Cierva y José Sánchez Guerra. En marzo de 1922 este último reemplaza en la jefatura del Gobierno a Maura.

En el otoño de ese año se vive un nuevo episodio del largo conflicto ${ }^{18}$ entre oficiales africanistas y junteros. La repercusión mediática del mismo es utilizada como detonante por la derecha autoritaria para provocar una crisis política que pretende, tal vez, forzar la vuelta de Maura a la jefatura del Gobierno, y, con seguridad, impedir que en el parlamento llegue a debatirse en torno a las responsabilidades por el desastre de Annual, lo que dañaría la imagen del ejército y los intereses colonialistas, así como crear el clima adecuado para que el rey se decida a nombrar o aceptar un Gobierno que gobierne sin el parlamento y dé continuidad de forma exitosa a la campaña militar en Marruecos. Con fecha de 15 de septiembre ${ }^{19}$ el jefe de la Legión se dirige por escrito al jefe del Gobierno y ministro de la Guerra, Sánchez Guerra: le dice que después de mucho reflexionar ha llegado a la conclusión de que «la nación se encuentra divorciada de su Ejército y que no lo aprecia» (léase que la sociedad civil debe acomodarse al modelo de los militaristas), que el arma de infantería se halla dividida y la

17. "Significación del triunfo fascista", La Acción, 31 de octubre de 1922.

18. Puede seguirse en MADRD, F, El ruidosisimo pleito de las Juntas de Defensa y Millán Astray, Barcelona, s.a. (1922).

19. Los movimientos de Millán Astray durante estos días serán dados a conocer por el propio jefe de la Legión, obviamente la versión que a él le interesa, en el mes de noviembre. $A B C, 10$ de noviembre de 1922. 
intranquilidad espiritual se ha apoderado de los oficiales. En octubre varios diarios, entre ellos Heraldo de Madrid, El Sol y La Acción, informan de una reunión mantenida por los directivos de las Juntas entre cuyos acuerdos figura la adopción de medidas discriminatorias para con los jefes y oficiales del Tercio, y también de la aparición de divergencias internas en el seno de la citada organización; la mayor parte de la prensa se muestra muy crítica con las Juntas y el Gobierno comienza a valorar su disolución con el argumento de que perturban la imagen y la necesaria unidad del ejército. Millán Astray se dirige entonces por segunda vez al jefe del ejecutivo, al que transmite el sentir de los africanistas: "el presidente de la Junta de Infantería ha decretado nuestra persecución y exterminio», "el estado del espíritu del Ejército requiere un cambio radical del sistema moral por estar influido por la derrota, por la falta de aptitud con que llegó el Ejército de socorro a Melilla, por la extensión y dificultades de la guerra de Marruecos, por permanecer aún los prisioneros sin rescatar, por el triste concepto internacional que de España se tiene». Además, Millán Astray solicita y obtiene permiso para viajar a Madrid, donde asiste a una serie de actos sociales invitado por los promotores de los africanistas en la capital del Estado ${ }^{20}$.

El 17 de octubre los junteros boicotean el homenaje que en la caseta del Círculo de Labradores de Sevilla se celebra en honor de González Carrasco, jefe de los Regulares de Larache, nacido en esa ciudad. Al homenaje asiste el jefe del Gobierno, el general Sanjurjo, que ha mandado las columnas que operan en la comandancia de Melilla, y otros oficiales venidos desde el protectorado, pero faltan muchos de los oficiales con destino en las guarniciones próximas. No obstante, lo más destacado de ese evento termina siendo el hecho de que el jefe del Gobierno prohíba que se dé lectura a un telegrama de adhesión enviado por Millán Astray, señalando que entra en temas que no son de su competencia. Antes del brindis, y en un ambiente de tensión, el jefe del ejecutivo dirige unas palabras a los allí reunidos: lamenta las ausencias, exige disciplina al ejército en su conjunto, señalando que se trata de un deber militar, como el de morir por la patria, y declara que él renuncia a los efectos teatrales que tanto gustan a algunos, en clara alusión a Millán Astray.

Éste no ha asistido al citado homenaje, pero ya sabemos que se encuentra en Madrid. Quienes alientan su afán de protagonismo también se encargan de que la prensa publique que el 18 ha visitado al rey en palacio. Ante los muchos periodistas que le esperan a las puertas del palacio de Oriente, un efecto buscado, Millán Astray manifiesta haber acudido a ofrecer sus respetos a sus majestades antes de regresar a su destino y para hablar con el monarca de un acto impulsado por la oficialidad legionaria, que habría de celebrarse al mes siguiente en Madrid: una parada militar con la participación de legionarios a punto de licenciarse y la entrega por la reina Victoria de una bandera a la Le-

20. La Acción, que recoge muchos datos sobre las idas y venidas de Millán Astray, dice el día 14 de octubre que ha asistido a una comida en Chinchón y a una cacería en otro lugar próximo a Madrid. 
gión, concedida en premio a su labor en la campaña y homenaje a sus muertos. Esa visita no gustó nada al Gobierno y ante los rumores puestos en circulación, el subsecretario del Ministerio de la Guerra se verá obligado a convocar a los periodistas para decirles que, en contra de lo publicado en algunos medios, el Gobierno no había ordenado al teniente coronel Millán Astray abandonar Madrid, que el jefe de la Legión no ha rectificado "porque la disciplina no consiste en rectificar» (no aclara lo que debía ser rectificado), y, respecto a un posible enfrentamiento entre el jefe del Gobierno y el jefe de la Legión, quien a la fuerza tiene que haber estado respaldado por jefes de mayor graduación, que "se exagera más de lo debido ${ }^{21}$.

\section{La derecha autoritaria encumbra a Millán Astray}

El 1 de noviembre Millán Astray, ahora desde Melilla, vuelve a dirigirse por carta al jefe del Gobierno. Le dice que al llegarle rumores a través de la prensa de que va a ser ascendido a coronel (no hemos localizado ese rumor), e interpretando que se le quiere apartar del mando del Tercio, ha escrito al ministro de la Guerra, general Barrera. En esa carta, supuestamente, le habría dicho: «mi deseo es todo lo contrario", rechazando así un ascenso que no parece que estuviera en marcha. Dice expresarse así porque le ha molestado enormemente que el alto mando haya dispuesto, en un reciente plan de operaciones, la asignación de cada una de las tres banderas legionarias con destino en la zona de Melilla a una columna diferente, con lo que él ha tenido que ejercer de jefe no de las tres sino de una sola; esta situación ya se había dado meses atrás, con José Sanjurijo como jefe de las columnas, y Millán Astray no había elevado ninguna protesta al respecto ni tenía derecho a ello. Asimismo se queja de que el alto comisario le ha comunicado la orden del Gobierno de suspender la entrega de la bandera que la reina había donado a los legionarios, con la excusa de que el país no vive el mejor momento para que los contingentes que habrían de dar escolta a la bandera en Madrid sean retirados del frente, aunque al parecer estaba prevista la participación de aquellos legionarios que cumplen su contrato en noviembre; añadía que había tenido acceso al despacho cifrado remitido por el ministro sobre esta cuestión: "Soy desde luego absolutamente contrario a la propuesta del jefe del Tercio Extranjero y considero injustificada y perjudicial esta presentación teatral en Madrid de los 586 legionarios que habrán de licenciarse, prohibiendo, por tanto, en absoluto, tal expedición». A partir de estas consideraciones Millán Astray demandaba del jefe de Gobierno una valoración sobre si debía pedir, o no, la baja en el ejército. Evidentemente le estaba presionando, enviándole el mensaje de que los africanistas estaban con él, y que veían en su acción un sacrificio, uno más, por la patria:

«le suplico, señor, haga llegar a mí el conocimiento suficiente para saber si es

llegado el momento de -con el mayor respeto y el más cruel de los dolores- pedir la

21. El Debate, 18, 19 y 20 de octubre de 1922; y ABC y La Accion. 
separación del Ejército, por juzgar ya mi situación insostenible en las circunstancias actuales».

Si hubo respuesta del jefe del Gobiemo Millán Astray optó por no dar publicidad a la respuesta. $Y$ en cualquier caso el contenido de la misiva no habría sido, no lo podía ser, suficientemente satisfactorio como para hacerle cambiar de parecer. Es entonces cuando varios oficiales de la Legión difunden rumores de que la oficialidad de esta unidad y de Regulares, en su totalidad, va a solicitar cambio de destino, y de hecho un comandante legionario cursa esa petición y otro solicita un año de permiso en el exterior ${ }^{22}$. Mientras tanto, la prensa vinculada al maurismo hace todo lo posible para enrarecer el ambiente. El Debate se hace eco de la división entre la oficialidad de infantería respecto a los ascensos, tema que es de sobra conocido, y apunta que los dirigentes de las Juntas han solicitado y obtenido del ministro de la Guerra la suspensión del acto de entrega de la citada bandera al Tercio. También apunta el recorte impuesto desde el ministerio a la autonomía que hasta el momento ha disfrutado Millán Astray para escoger a sus oficiales, dado que en el momento de la fundación de la Legión pudo llamar a los oficiales que él quiso y a continuación, y hasta este momento, proponer el nombramiento de quienes habrían de ocupar las vacantes, que ahora se cubren de manera automática. Esto habría dado lugar a un descontento traducido, al parecer, en solicitar la baja en el servicio con la excusa de enfermedades inventadas:

"Consecuencia de estos hechos se dice que son las licencias que por enfermedad han solicitado el teniente coronel Millán y el comandante Franco. Otros muchos oficiales piden el traslado y abandonan disgustados el Tercio ${ }^{23}$.

Por su parte La Acción sostiene que los cambios de destino realmente solicitados y aquellos sobre los que existen rumores serían en realidad cambios de destino impuestos desde el ministerio por la presión de las Juntas ${ }^{24}$, lo que es falso. Inmediatamente después Millán Astray viaja de nuevo a Madrid, con licencia por enfermedad, y el alto comisario, ante las preguntas de los periodistas, se ve obligado a declarar que el interesado ha viajado para curarse una fístula. No parece que sea así, pues Millán Astray se deja ver en la Gran Peña y en los cafés del centro de Madrid y, en plan provocador, desairando al ministro de la Guerra y al jefe del ejecutivo, declara a los periodistas (lo recoge El Debate), y así lo extienden sus allegados, que nunca se ha sentido tan bien como entonces. Lo que es evidente es que Millán Astray quiere estar en la capital para difundir a la prensa un manifiesto en el que dice verse obligado a solicitar el pase a la situación de retirado, al no poder aguantar más las injusticias que él y el conjunto de la Legión sufren a manos de los junteros, con el permiso del Gobierno, y después esperar acontecimientos; el contenido del texto y su difusión a la

22. $A B C, 5$ de noviembre de 1922 .

23. El Debate, 9 de noviembre de 1922.

24. La Acción, 6 de noviembre de 1922. 
prensa, que lo recoge el 10 de noviembre, supone saltarse todos los conductos reglamentarios para tratar temas militares. Pero podrá darse por satisfecho: consigue que los medios le presten una notable atención, en especial la prensa que alienta el colonialismo, de forma muy destacada la vinculada al maurismo. El Debate y La Acción se vuelcan a la hora de exaltar la figura de Millán Astray. En el primero leemos, el día 10, en un editorial titulado "La disyuntiva: Millán se ha visto obligado a separarse del ejército»:

«España entera contemplará con simpatía y admiración a este bravo caudillo que, en tiempos tan faltos de verdadero espíritu militar y patriótico, ha sabido ser el genuino representante de las gloriosas tradiciones de la Infantería española».

Una vez cubierta esta etapa, que forma parte de un plan más ambicioso de lo que a simple vista puede parecer, los dirigentes mauristas movilizan a sus bases, y con ellas a varios miles de estudiantes universitarios en diversos puntos de España. Con ello alientan un movimiento de protesta que parte de los mismos argumentos utilizados por el jefe de la Legión. Y lo hacen en el preciso momento en que las Cortes están a punto de reanudar sus sesiones, y debatir sobre las responsabilidades por el desastre de Annual a partir del expediente Picasso tan sólo unos días después de la llegada de los fascistas al poder en Italia, con el aplauso entusiasmado de la derecha autoritaria española. De hecho el autor del manifiesto se presenta como un militar sacrificado, dispuesto a abandonar su carrera (¿para dedicarse a la política?) por el egoísmo e ineptitud de la mayor parte de la clase política, y también de parte de los militares, es decir por los mismos motivos que según La Acción justificarían la violencia fascista. Millán Astray escribe lo siguiente:

«Pido mi retiro porque no quiero ni puedo continuar en el Ejército actuando en él dos poderes: uno legal, el del Gobierno, y otro subversivo, el de las Juntas de Defensa; yo sólo reconozco el Poder del Gobiemo y rechazo y me opongo al poder de las Juntas, y después de haber pedido mi retiro en una instancia que dice así.

"La bandera nacional que los legionarios esperaban recibir de las augustas manos de S. M la Reina, para adornar el santo emblema de la Patria con la medalla militar que ellos ganaron (...) no la recibirán por ahora; ni podrá acompañarles ya el que fue su teniente coronel.

Después de lo dicho, ya está explicada mi conducta ante la nación; ahora que todos me juzguen, propios y extraños, y hagan justicia»».

Como decíamos, una vez causado el efecto apetecido, y tras varias semanas clamando por la agitación de la calle y justificando el empleo de la violencia para llevar a cabo una revolución conservadora como la que alienta el fascismo, la derecha autoritaria, representada por Acción Católica y la Juventud Maurista, con el respaldo mediático de sus medios y de $A B C$, organiza una serie de manifestaciones, primero en Madrid, y a continuación en diferentes puntos del país. El motivo declarado es respaldar la figura de Millán Astray y exigir la supresión de las Juntas de Defensa. El objetivo real es el de desatar una crisis que, con el triunfo de la marcha sobre Roma y la designación de Benito Mussolini como jefe de Gobierno por el rey de Italia como trasfondo, decida al rey Alfonso XIII, na- 
da entusiasta del parlamentarismo, a confiar la jefatura del Gobierno a alguien, preferentemente Maura o un general, que ejerza su función con plenos poderes. A media mañana del día 10, el mismo día en que la prensa recoge esbozos o el texto completo del escrito de Millán Astray, estudiantes universitarios convocados por la Confederación de Estudiantes Católicos y la Juventud Maurista se concentran ante el domicilio de los padres de Millán Astray, donde éste reside cuando viaja a la capital. Como está previsto, tras escuchar las aclamaciones que le dirigen, el militar sale al balcón y les lanza una arenga, fiel a su estilo. Después los estudiantes se dirigen hacia el edificio de presidencia del Gobierno, donde lanzan gritos a favor de Millán Astray y la Legión y contra las Juntas y el Gobierno. Por la tarde unos 400 estudiantes (datos de $A B C$ ) se concentran en la Puerta del Sol, con las mismas intenciones. El Gobierno ordena entonces a la policía cortar de raíz las concentraciones. Ante la presión policial los manifestantes marchan por las principales arterias del centro de Madrid hasta el Círculo del Ejército y la Armada, en la calle de Alcalá, donde se organiza un nuevo tumulto, y fuerzas de la policía a caballo disuelven a los manifestantes. Éstos se dirigen entonces, por segunda vez, a la casa de Millán Astray, pero no pueden acceder a sus inmediaciones por estar cercada por efectivos policiales. Quien sí ha estado en el domicilio ha sido Goicoechea, de quien la prensa que le es adicta dice que ha dirigido unas palabras a los oficiales reunidos en casa de Millán: "La actual situación no puede durar una hora más. Es hora ya de que se distingan los buenos de los malos y se dé una batalla decisiva. Creo que el Gobierno no puede tardar ya un minuto más en acabar con las Juntas» ${ }^{25}$. Para entonces, como en semanas anteriores, circulan varios rumores sobre los propósitos y maniobras de Millán Astray y de las medidas del Gobierno para neutralizar a este adversario, que en realidad son muy tímidas por el temor de los gobernantes a tomar decisiones frente a los militares díscolos o insubordinados sin contar con el beneplácito del monarca, algo que casi nunca llega. Se dice que Millán Astray ha hablado con el rey, cuando lo cierto es que lo ha hecho con uno de los ayudantes del monarca, y que ha sido detenido, lo que no es cierto, pero sí lo es que se le han instruido diligencias, para apreciar si se ha producido extralimitación de las ordenanzas militares que prohíben a los militares hacer declaraciones a la prensa ajenas a su condición, y que ha sido citado para prestar declaración en el cuartel de la Montaña.

En la primera página de su edición correspondiente a la noche del $10 \mathrm{La}$ Acción sitúa una foto de Millán Astray en la que éste aparece riéndose, y la junta directiva de la Juventud Maurista anuncia la convocatoria en Madrid de "una gran manifestación cívica». Al día siguiente el militar, más serio, ocupa la portada de $A B C$ y en el interior del diario Corrochano le dedica el artículo, "Adhesiones y protestas", con un epígrafe titulado "El odio a los Héroes». El 11 se movilizan los estudiantes vinculados a las organizaciones católicas. En Madrid acuden a la Universidad Central, pero, en contra de los planteamientos

25. El Debate, 11 de noviembre de 1922. 
que en otras ocasiones han defendido, buena parte de ellos desisten de acudir a las clases y se concentran en torno a la estatua de Colón, a donde también llegan dirigentes de la Juventud Maurista, como Goicoiechea, Santos Ecay y el concejal por Madrid y diputado a Cortes, Alfredo Serrano Jover. La intervención policial obliga a los manifestantes a disolverse con rapidez. Unas horas después una comisión de la Confederación Nacional de Estudiantes Católicos, que ha conseguido que la mayoría de estudiantes apruebe una convocatoria de huelga por tres días, del 13 al 15, acude a casa de Millán Astray, donde según El Debate, se han reunido varios oficiales legionarios, lo que resulta extraño e improbable dado que tienen otros destinos, y el periodista Ruiz Albéniz.

\section{La Legión como referente de los promotores del fascismo en España}

La manifestación maurista, que debía celebrarse el domingo día 12 en la madrileña plaza de Colón, no fue autorizada por el Gobierno. Sin embargo, allí se concentran, haciendo uso de la calle, como en Italia, varios cientos de simpatizantes de esta derecha autoritaria y deslumbrada por la conquista del poder por el fascismo a la que nos venimos refiriendo. Tras ser disueltos por la policía los manifestantes se dirigen hacia el centro, donde los agentes se emplean a fondo y detienen al menos a veinte personas; varios estudiantes resultan heridos: según $A B C$ cinco han sido alcanzados por disparos de la policía. El 13 se producen más incidentes, ahora en la zona de la Universidad, donde grupos de estudiantes se concentran para protestar por la actuación de las fuerzas de seguridad, acostumbradas a cargar contra militantes de la izquierda o protagonistas de protestas sociales relacionadas con las malas condiciones de vida de los trabajadores manuales y clase media baja. Ante la presión policial los estudiantes se refugian en la Facultad de Medicina, en la calle de Atocha, y arrojan piedras y ladrillos desde ventanas y balcones. La policía hizo visibles sus armas de fuego, sin llegar a utilizarlas, y procedió a detener a 28 estudiantes, que serán puestos en libertad tras prestar declaración. Otras algaradas se suceden en la zona de la Castellana y el centro urbano, y un estudiante resulta herido de un sablazo en la cabeza ${ }^{26}$. La Acción se apresta a justificar la acción de los estudiantes, ejemplo de la violencia que, como en Italia, es necesaria en España:

"Dada la forma en que los guardias se comportaban, obedeciendo sin duda órdenes superiores, los estudiantes subieron al tejado de la Facultad e iniciaron una verdadera lluvia de tejas".

El día $14 A B C$ publica el texto del telegrama remitido por el comandante Franco a Millán Astray, el cual transmite el apoyo de la oficialidad de la Legión a su jefe: "Oficiales de estas banderas le acompañan todo momento identificados». En Madrid y otras capitales se suceden las protestas contra las Juntas en las calles, o por lo menos ésa es la imagen que pretenden difundir los partidarios de la guerra y la empresa colonial: "Manifestaciones y alborotos en las calles»,

26. El Debate, 14 de noviembre de 1922. 
leemos en el citado diario, en referencia a la protesta estudiantil en Valencia, Cádiz, Salamanca, Zaragoza y Oviedo, además de Madrid. En la capital tienen lugar los incidentes más graves: el 15 un guardia hace fuego contra un grupo de estudiantes en los aledaños de la Facultad de Medicina y seis resultan heridos y, como protesta, las autoridades académicas deciden mantener cerrada la Universidad durante varios días. Los medios próximos al maurismo hablan de 1.500 manifestantes dando gritos ante la casa del jefe del Gobierno el día 12, y de 3.000 manifestantes en el centro de la capital el día 13, de las cargas de los guardias a caballo, de los detenidos y se inventan un estudiante muerto como resultado de la represión policial ${ }^{27}$. El Gobierno pretende calmar la situación con una solución salomónica: a mediados de noviembre pasa a Millán Astray a la situación de disponible y presenta en las Cortes un proyecto de ley que disuelve las Juntas de Defensa y prohíbe a los militares formar parte de asociaciones que tengan fines relacionados con el servicio, obteniendo, como era sabido, un amplio respaldo en la cámara y en los medios de comunicación. Pero la derecha maurista prosigue agitando la calle.

Pese a que es evidente que se busca exagerar la magnitud de la protesta, no hay duda de su impacto, y de la sorpresa que causa en medios de la izquierda. Así se percibe en las páginas de El Socialista. Este diario presenta a los estudiantes, sin distinciones, como señoritos favorables al militarismo: «Apenas comenzado el curso, los estudiantes han dado ya pruebas de su fastidio por las aulas universitarias. La ocasión era propicia para un alarde de patrioterismo ${ }^{28}$. Además, apunta la acción de "excitadores de las algaradas estudiantiles» y denuncia, una vez desaparecidas las Juntas, la aparición de

«otro poder militar que hace lo que le da la gana sin respeto a la disciplina, y se permite al jefe del Tercio hacer una alocución a los alcaldes y a los ciudadanos todos para levantar la opinión y entonces empieza a agitarse la vida política en torno a ideas confusas, y se ejerce una acción meditada, organizada, sobre las masas de estudiantes».

Por su parte el dirigente socialista Julián Besteiro, profesor en la Universidad Central, interviene en las Cortes y se refiere al tema que tratamos. Su discurso, en el que leemos que "han sido los mauristas los que han convocado a la juventud para una manifestación públican, traduce la sorpresa que existe en medios de la izquierda por el recurso a la calle por un sector de la derecha, y el reconocimiento de que la movilización ha sido notable, así como la nula influencia de los socialistas, y de la izquierda en general, sobre las organizaciones estudiantiles. Después incide sobre el por qué de lo que está ocurriendo:

"Aquí de lo que se trataba no era de la disolución de las Juntas, ni siquiera de los homenajes al Tercio; aquí de lo que se trataba era de crear dificultades políticas por las cuales no se pudiera abrir el Parlamento ¿Por qué? Porque el problema actual,

27. La Acción, 13 de noviembre de 1922; el 17 tuvo que reconocer que ese estudiante había fallecido a causa de un accidente de motocicleta.

28. El Socialista, 10 de noviembre de 1922. 
señor conde de Romanones, no es el de las Juntas: es el expediente Picasso, y todo lo que se haga para enturbiar las aguas de la política en el momento actual no puede tener otra significación que procurar que se entierren en el olvido las responsabilidades graves y de altura que del expediente Picasso se derivan ${ }^{29}$.

Especialmente agudo en su análisis se muestra Miguel de Unamuno en uno de los artículos que entonces publica en las páginas del diario socialista. Unamuno traduce fascio (haz, gavilla) por fajo, de forma que el movimiento fascista en España debería recibir el nombre de fajismo, y se muestra convencido de que este movimiento ya está en marcha. Lo encuentra en la Juventud Maurista en alianza con los mandos de la Legión, con dos personajes a su frente, Goicoechea y Millán Astray, y si el primero fuera el encargado de agitar la calle y desestabilizar definitivamente la vida política, el segundo podría encargarse de proporcionar la fuerza militar necesaria para garantizar el triunfo de la dictadura, sin que aparentemente, como en Italia, fuera preciso que un golpe militar se hiciera visible: «Los despechugados de Millán Astray son los camisas negras de Mussolini ${ }^{30}$. Se trata evidentemente de símbolos para explicar la crisis a la que venimos refiriéndonos. En realidad, la derecha autoritaria carece en España de fuerza suficiente como para ocupar las calles según el patrón del fascismo italiano, lo que explica el recurso al ejército, ahora y en la década siguiente. No obstante, se apunta un éxito menor, y sin que los méritos sean sólo suyos: la dimisión en diciembre de Sánchez Guerra, arrastrado por la presentada por dos ministros que formaron parte del gobiemo del desastre, y su sustitución por un Gobierno de concentración liberal que encabeza Manuel García Prieto. Será otro Gobierno carente de respaldos sociales, dada la corrupción del sistema caciquil y la existencia de un parlamentarismo sin democracia. Además, es sabido que el rey está evaluando la posibilidad de encabezar un Gobierno dictatorial $y$, lo que es lo mismo, en la prensa se airean cada vez más rumores de un golpe militar.

Pero la metáfora es de alguna forma válida. Millán Astray ha asumido un protagonismo que algunos califican de teatral pero que no ha dejado de ser efectivo y le ha dado una gran visibilidad pública, algo que el personaje busca, tal vez viendo en sí mismo, antes de sufrir las graves mutilaciones que le causarán dos heridas en el frente, el Mussolini español que un sector de la derecha ansía. Los mauristas, con Goicoechea en el papel estelar, también se han sentido protagonistas, $y$ han intentado reconvertir el movimiento maurista en un fascismo a la española; aunque no sólo los mauristas trabajan en esa dirección ${ }^{31}$. El 16 de diciembre aparece, editada en Madrid, La Camisa Negra, que, además de reivindicar el color de la camisa de las escuadras fascistas, aboga por un «brazo de

29. El Socialista, 18 de noviembre de 1922.

30. "El fajismo en el reino de España", El Socialista, 28 de noviembre de 1922.

31. Sobre, en el ámbito catalán, La Traza, Juventud Nacionalista Española y la Peña Ibérica, véase CUlla I ClARÀ, J. B., "L'extrema dreta a Catalunya durant la República. El ultres d'abans de la guerra", L'Aven , n. $^{\circ} 6$ (octubre 1977), pp. 48-50; CASTILlo, J. del y ÁLVAREZ, S., Barcelona, objetivo cubierto, Barcelona, 1958, p. 115; y el ya citado artículo de Enric Ucelay Da Cal. 
hierro que levante muy en lo alto el estandarte nacional e imponga y haga cumplir a todos un programa de economía, trabajo y disciplina». Esta publicación es fruto de la labor desarrollada por el maurista Santos Ecay, con financiación a cargo de la Confederación Patronal Española, cuyo portavoz, El Eco Patronal, ha reclamado ya un "Mussolini español». Mayor continuidad tiene el esfuerzo hecho desde las páginas de La Acción, que, una vez que los estudiantes afiliados a la Federación de Estudiantes Católicos regresan a las aulas, anima a sus lectores a avanzar "por la senda del fascismo".

Para los mauristas «jamás ha habido un ambiente como el de ahora para una obra patriótica de moralización y engrandecimiento". En consecuencia, para aprovechar esta coyuntura, en la que el jefe y oficiales de la Legión han sido presentados por los medios interesados en ello como un referente de vigor nacional y de valentía, capaces de gritar ;Viva la muerte!, un grito aplicable a la vida civil, La Acción hace una nueva tentativa de captación, sustituyendo las denominaciones Juventud Maurista y fascismo a la española por la de Legión nacional, fórmula con la que se busca disimular la imitación de un modelo extranjero (años después se utilizará la denominación Falange Española), si bien se reconoce que "a una legión así se ha llamado en Italia fascismo»32. Pero ese fascismo apenas obtiene apoyos, como evidencia la aparición de un solo número de La Camisa Negra y la muy escasa proyección de La Traza, publicación filofascista editada en Barcelona. Las declaraciones, reiteradas, de Goicoechea, pensando en sí mismo, en las que afirma que «hombres de la derecha y de la izquierda hacen votos para que surja en España un Mussolini», no encuentran el eco buscado. Pues, aparte de la competencia por el liderazgo en la derecha antiliberal, el fascismo a la española apenas despierta interés entre la clase política, ni siquiera en el entorno del conservadurismo, que ha evolucionado ya hacia el antiparlamentarismo siguiendo las directrices francesas pero que opta por el militarismo frente al fascismo. Los mauristas se verán obligados a reconocer su limitada capacidad para movilizar a las clases medias españolas, grupo social limitado en términos numéricos en relación a la amplitud del proletariado obrero y campesino, y además dividido políticamente. Tendrán que limitarse a esperar a que en septiembre del año siguiente tenga lugar un pronunciamiento militar que liquida el parlamentarismo y da protagonismo político a una parte de sus huestes. Obviamente, el triunfo del golpe de Primo de Rivera y la continuidad del régimen dictatorial durante seis años cercena, por el momento, las posibilidades del fascismo a la española.

\section{EPILOGO}

No hay en los textos publicados por los jefes legionarios, ni en Diario de una bandera, ni en La Legión, a cargo de Millán-Astray en 1923, opiniones a favor de una organización o corriente política concreta, no pudiendo valorarse como tal

32. Editoriales del Duque de G, La Acción, «La Legión nacional» (16-11-1922) y «La legión nacional. El estímulo de un gran ejemplo» (18-11-1922). 
la exaltación del credo legionario. Tampoco parece haberlas en sus declaraciones a la prensa, si nos atenemos al hecho de que Millán Astray no entra en valoraciones ni del maurismo ni del fascismo. Sin embargo, su proceder y algunas de sus declaraciones a los periodistas reflejan su rechazo a los procedimientos del parlamentarismo, y no hay duda de que existe una sintonía ideológica y de intereses entre el maurismo y el conjunto de la derecha antiliberal y los jefes de la Legión (Franco lo será en junio de 1923). Y desde luego, en determinados ámbitos de la derecha, la que promueve una organización fascista, la Legión aparece como un referente. Es decir, y éste terminará siendo el elemento más trascendente, lo que encarna la Legión en tanto que fuerza de choque (escuadras de combate, fuerzas de asalto, en la terminología del fascismo) va a ser muy valorado en los años siguientes por un sector de la derecha ${ }^{33}$, con especial intensidad por quienes han de asumir el fracaso del primer fascismo español (1922-1923), y también de la segunda oleada fascista (1930-1936). Ya no sólo como representación del modelo apetecido para una milicia civil, sino en términos de unidad militar victoriosa en Marruecos, y, en 1934, en Asturias. Al mismo tiempo el papel desempeñado por el ejército de África en la sublevación militar de julio de 1936 y en el transcurso de los primeros meses de la contienda, y el hecho de que el general vencedor en la guerra haya sido comandante de la I bandera y jefe de la Legión hace que esta unidad se convierta en uno de los símbolos iconográficos del régimen de Franco. Pero no sólo por lo que Franco representa, también porque existe una identidad nacida tres lustros atrás y, aunque de forma intermitente, alimentada por la derecha antiliberal.

33. BAlfour, Sebastián, Abrazo mortal. De la guerra colonial a la Guerra Civil en España y Marruecos (1909-1939), Barcelona, 2002, y Nerín, Gustau, La guerra que vino de África, Barcelona, 2005, y Rodríguez, José Luis, jA mi la Legión!..., op. cit. 